\title{
Physiochemical Responses and Cold Survival Mechanism of Rice Seedlings of Selected Cultivars in Northwest Bangladesh
}

\author{
Bikash Chandra Sarker ${ }^{1, *}$, Sumaiya Aktar ${ }^{1}$, Prodip Kumar Roy ${ }^{2, *}$ \\ ${ }^{1}$ Department of Agricultural Chemistry, Faculty of Agriculture, Hajee Mohammad Danesh Science and Technology University, Dinajpur, \\ Bangladesh \\ ${ }^{2}$ Department of Chemistry, Biology and Marine Science, University of the Ryukyus, Nishihara-cho, Okinawa, Japan
}

\author{
Email address: \\ bikash@hstu.ac.bd (B. C. Sarker), prodipkroy@gmail.com (P. K. Roy) \\ ${ }^{*}$ Corresponding author
}

\section{To cite this article:}

Bikash Chandra Sarker, Sumaiya Aktar, Prodip Kumar Roy. Physiochemical Responses and Cold Survival Mechanism of Rice Seedlings of Selected Cultivars in Northwest Bangladesh. American Journal of Plant Biology. Vol. 5, No. 2, 2020, pp. 25-29.

doi: 10.11648/j.ajpb.20200502.13

Received: April 6, 2020; Accepted: April 29, 2020; Published: July 4, 2020

\begin{abstract}
Cold stress at seedling stage is a serious concern to the sustainable rice production in some regions of the world. A field experiment was carried out to investigate the physiological parameters of seedlings of selected five rice cultivars, namely Binadhan-6, BR-26, BRRI dhan28, BRRI dhan29, and BRRI dhan50 (Banglamoti) for cold survival mechanism during low temperature in the Northwest Bangladesh. The field experiment was arranged following Randomized Complete Block Design (RCBD) with three replications. The physiological parameters such as leaf proline, chlorophyll, total carotenoid content, relative water content (RWC) and starch were determined. In this study, the rice cultivars showed significant variation of physiological activities at low temperature. BRRI dhan28 synthesized the highest amount of proline $\left(1.25 \mathrm{mg} \mathrm{g}^{-1}\right)$, chlorophyll-a $\left(2.63 \mathrm{mg} \mathrm{g}^{-1}\right)$, chlorophyll-b $\left(0.85 \mathrm{mg} \mathrm{g}^{-1}\right)$, relative water content $(93.33 \%)$ and starch $(28.21 \%)$ content. Significant variability was observed among the cultivars during the experiment time for their survivability. The sequence of survival potentiality was observed as BRRI dhan28> BRRI dhan29> BR-26> BINA dhan-6> BRRI dhan50. The present finding infers that BRRI dhan28 showed the best survival potentiality based on the synthesis of proline, chlorophyll and other physiological parameters.
\end{abstract}

Keywords: Chlorophyll, Cold stress, Proline, Rice seedling, Starch

\section{Introduction}

Bangladesh is the most vulnerable to climate change for its geographical location and facing extreme weather like, longer winter chilling cold, hot and higher temperature during summer, uneven precipitation during boro and other crop season, frequent storm, cyclone, tornado, strong western wind. The Northwest Bangladesh is more susceptible to climate change effects especially sudden cold wave and chilling stress in winter affects rice seedling growth in Northwest Bangladesh. These effects are mostly related with food production resulted in threatening to food security in Bangladesh. Currently, rice is the second most consumed cereal in the world and production losses caused by extreme temperature events in the context of major climatic changes can have major impacts on the world economy [7].

Cold temperature, a common environmental stress in the temperate zone, affects numerous biochemical, physiological, and metabolic functions in plants [3, 5]. A numerous research works has been carried out worldwide with low temperature stress on rice crop $[1,2,10,13,21]$. Cold stress at seedling stage is a major constraint in boro rice production [9]. Seedlings subjected to prolonged exposure to chilling stress (i.e., several days to weeks) can exhibit necrosis and mortality while shorter or intermittent exposure often leads to yellowing (chlorosis) and stunting [22]. Compared to other cereal crops such as wheat (Triticum aestivum) and barley (Hordeum vulgare), rice is much more sensitive to low temperature as its tropical origin [20]. Low temperature at the seedling stage can 
result in poor germination, stunted, yellowing or withering, and reduced tillering as reported by Tuteja et al. 2012 [14].

Many tropical and subtropical plants are injured or killed by exposure to low chilling temperatures in the range of below about $10-12^{\circ} \mathrm{C}$, whereas others may tolerate temperatures below $0^{\circ} \mathrm{C}$ without exhibiting deleterious effects [4] while cold acclimation is an enhanced tolerance to the physical and physicochemical vagaries of freezing stress [12]. The chilling effect is manifested by physiological perturbations, generally called low-temperature injury [23, 25]. Catabolism of proline in stress free conditions generates reducing equivalents especially ATP to repair stress-induced damage $[15,16]$. The ratio of chlorophyll-a and chlorophyll-b is directly related to temperature. Its content in plant varies in relation to temperature change [17].

As the cold environment has numerous adverse effects on raising rice seedling as well as on rice production, it is utmost necessary to screen out cold tolerant rice cultivars suitable for the boro season cultivation in Northwest Bangladesh where frequent cold wave is observed in the month of December and January. Therefore, the research work was carried out to investigate the physiological and biochemical characteristics of rice seedlings under cold environment for understanding the mechanism of chilling survival mechanism.

\section{Materials and Methods}

\subsection{Planting Materials and Experimental Design}

The study was conducted at the agriculture research field of Hajee Mohammad Danesh Science and Technology University, Dinajpur, Bangladesh located in $25.13^{\circ} \mathrm{N}$ latitude and $88.23^{\circ} \mathrm{E}$ longitude and at an elevation of $34.5 \mathrm{~m}$ above the mean sea level. The experimental field soil was the Old Himalayan piedmont plain soil belonging to Agro Ecological Zone 1 (AEZ-1). The selected rice cultivars were BINA dhan-6, BR-26, BRRI dhan28, BRRI dhan29, BRRI dhan50 (Banglamoti). The field experiment was designed following Randomized Complete Block Design (RCBD) with three replications. The research work was conducted during December to February which is also known as dry season or Rabi season. The air temperature was relatively low at the beginning of the season and was lowering with advancement of the experiment (range, $4-25^{\circ} \mathrm{C}$ ), followed by subsequent increasing with occasional gusty winds. No rainfall was detected during the experimental period.

\subsection{Physiological Parameters}

The leaf samples for analyzing proline, chlorophyll pigments and RWC were collected from the experimental plot at four days interval starting from 16 days to 24 days after sowing (DAS). The determination of starch content in seedling was done once at 24 DAS. For proline content, $50 \mathrm{mg}$ fresh leaf samples from rice seedlings at 16, 20 and 24 days after sowing was collected in a $2-\mathrm{mL}$ eppendorf tube. Free leaf proline content was estimated by following acid ninhydrin method described by Thomashow 1999 [11]. Determination of leaf pigments (chlorophyll-a, chlorophyll-b and total carotenoid) content was performed by following [6] and total chlorophyll was estimated by Porra 2002 [19]. The RWC measurement was carried out using by standard method. The starch content of rice seedling was determined by Fehling's solution method.

\subsection{Statistical Analysis}

The collected data were analyzed statistically for the analysis of variance (ANOVA) and means were compared by Duncan's Multiple Range Test (DMRT) as described using the statistical computer package program MSTAT-C.

\section{Results and Discussion}

\subsection{Proline Content}

Crop plants have a number of mechanisms to cope with stresses in their environment. The defense mechanism of rice seedling to low temperature condition is still unexplored or in initial stages. The synthesis of leaf proline in the rice seedlings of different cultivars during the experiment period is shown in the Table 1. The seedlings of BRRI dhan28 synthesized the highest proline content in leaves than those of other cultivars at 16 DAS, 20 DAS and 24 DAS. It is evident the rice seedlings tended to accumulate higher proline during cold temperature. The proline is regarded to have multiple roles in stress tolerance in most of the plants. The proline is considered as key factors in metabolism and development of higher plants $[16,24]$.

Table 1. Proline $\left(\mathrm{mg} \mathrm{g}^{-1}\right)$ synthesis by rice seedlings of different cultivars at different DAS during the experiment.

\begin{tabular}{llll}
\hline Cultivars & 16 DAS & 20 DAS & 24 DAS \\
\hline Binadhan-6 & $0.643 \mathrm{~b} \pm 0.09$ & $0.667 \mathrm{~b} \pm 0.30$ & $0.546 \mathrm{~b} \pm 0.24$ \\
BR-26 & $1.060 \mathrm{ab} \pm 0.07$ & $0.914 \mathrm{ab} \pm 0.21$ & $0.560 \mathrm{~b} \pm 0.06$ \\
BRRI dhan28 & $1.251 \mathrm{a} \pm 0.18$ & $1.229 \mathrm{a} \pm 0.35$ & $1.239 \mathrm{a} \pm 0.08$ \\
BRRI dhan29 & $0.904 \mathrm{ab} \pm 0.42$ & $0.587 \mathrm{~b} \pm 0.12$ & $0.785 \mathrm{ab} \pm 0.70$ \\
Banglamoti & $0.759 \mathrm{~b} \pm 0.19$ & $0.523 \mathrm{~b} \pm 0.10$ & $0.559 \mathrm{~b} \pm 0.08$ \\
\hline
\end{tabular}

Mean followed by the same letter (s) did not differ significantly at $5 \%$ level by DMRT and \pm values are for standard deviation.

The proline content in rice seedlings was differently altered with the fall in temperature. There was only a slight increase in the content of proline at slow increase in air temperature in BRRI dhan28 compared to the other cultivars. The accumulation of proline in BRRI dhan 28 variety was the highest among the cultivars tested here. The result suggested that the increased proline content might be associated with cold tolerance.

\subsection{Total Chlorophyll Content}

In this study, the total chlorophyll content of selected rice cultivars was varied significantly during the experimental period which is shown in Table 2. The highest chlorophyll content was in BRRI dhan28 at 16, 20 and 24 DAS but the lowest was in Binadhan-6 cultivars at 16 and 24 DAS while 
BRRI dhan29 at 20 DAS. The total chlorophyll content of Binadhan- 6 rice seedling at 16,20 , and 24 DAS were 1.455 , 1.687 and $1.782 \mathrm{mg} \mathrm{g}^{-1}$, respectively, when the environmental temperature was below $12^{\circ} \mathrm{C}$ (Data not shown).

The decrease in chlorophyll content under cold stress has been considered a typical symptom of oxidative stress and may be the result of pigment photo-oxidation and chlorophyll degradation. The present study indicated that some of the tested cultivars produced greater amount chlorophyll-a that was important for survival capability during low temperature (Table 2). Sarker et al. (2015) stated that some rice cultivars withstood cold stress by increased synthesis of chlorophyll at seedling stage. Among the cultivars they studied, BRRI dhan 28 produced the highest and might have cold tolerance potentiality chilling cold.

Table 2. Total chlorophyll content $\left(m g g^{-1}\right)$ in rice seedlings of different cultivars at different DAS.

\begin{tabular}{llll}
\hline Cultivars & 16 DAS & 20 DAS & 24 DAS \\
\hline Binadhan-6 & $1.455 \mathrm{~b} \pm 0.25$ & $1.687 \mathrm{c} \pm 0.25$ & $1.782 \mathrm{c} \pm 0.18$ \\
BR-26 & $2.275 \mathrm{a} \pm 0.16$ & $2.429 \mathrm{ab} \pm 0.58$ & $2.074 \mathrm{bc} \pm 1.19$ \\
BRRI dhan28 & $2.509 \mathrm{a} \pm 0.12$ & $2.825 \mathrm{a} \pm 0.35$ & $3.355 \mathrm{a} \pm 0.97$ \\
BRRI dhan29 & $1.620 \mathrm{~b} \pm 0.16$ & $1.294 \mathrm{c} \pm 0.37$ & $2.489 \mathrm{~b} \pm 1.23$ \\
Banglamoti & $2.346 \mathrm{a} \pm 0.09$ & $1.766 \mathrm{bc} \pm 0.28$ & $2.196 \mathrm{bc} \pm 1.58$ \\
\hline
\end{tabular}

\subsection{Chlorophyll-a Content}

In this study, a significant difference in chlorophyll-a content was found among the seedlings of selected rice cultivars. The variability of chlorophyll-a content in rice seedlings is shown in Table 3.

Table 3. Chlorophyll-a $\left(m g g^{-1}\right)$ synthesis by rice seedling of different cultivars at different $D A S$.

\begin{tabular}{llll}
\hline Cultivars & 16 DAS & 20 DAS & 24 DAS \\
\hline Binadhan-6 & $1.204 \mathrm{~b} \pm 0.27$ & $1.287 \mathrm{bc} \pm 0.25$ & $1.383 \mathrm{~b} \pm 0.19$ \\
BR-26 & $1.923 \mathrm{a} \pm 0.06$ & $1.580 \mathrm{~b} \pm 0.36$ & $1.558 \mathrm{~b} \pm 0.52$ \\
BRRI dhan28 & $2.148 \mathrm{a} \pm 0.09$ & $2.136 \mathrm{a} \pm 0.15$ & $2.630 \mathrm{a} \pm 0.56$ \\
BRRI dhan29 & $1.346 \mathrm{~b} \pm 0.18$ & $1.004 \mathrm{c} \pm 0.27$ & $1.879 \mathrm{~b} \pm 0.44$ \\
Banglamoti & $1.933 \mathrm{a} \pm 0.13$ & $1.314 \mathrm{~b} \pm 0.12$ & $1.659 \mathrm{~b} \pm 0.33$ \\
\hline
\end{tabular}

In this study, the highest chlorophyll-a content was in BRRI dhan28 (2.630 $\left.\mathrm{mg} \mathrm{g}^{-1}\right)$ and the lowest value was observed in BRRI dhan29 (1.004 $\left.\mathrm{mg} \mathrm{g}^{-1}\right)$ at $20 \mathrm{DAS}$, respectively. The biosynthesis of chlorophyll-a in BRRI dhan28 considered the superior among the cultivars studied during the experimental period. Similar variation in chlorophyll-a content in different rice cultivars at low temperature during seedling growth stage was revealed by Sarker et al 2015 [3]. Thus, the cultivar having more chlorophyll content during low temperature environmental condition is considered as more low temperature tolerant due to their higher photosynthesis ability. In the present study, BRRI dhan 28 rice seedlings might have potentiality to withstand low temperature for their survival.

\subsection{Chlorophyll-b Content}

The chlorophyll-b content in seedling leaves under low temperature environment in the study area has been presented in Table 4. Chlorophyll-b absorbs energy from wavelengths of green light at $640 \mathrm{~nm}$. It is the accessory pigment that collects energy and passes it on to chlorophyll-a. In this research work, the highest chlorophyll-b content was in BRRI dhan28 (0.847 $\left.\mathrm{mg} \mathrm{g}^{-1}\right)$ and the lowest was observed in BRRI dhan29 $(0.289 \mathrm{mg}$ $\left.\mathrm{g}^{-1}\right)$ at 20 DAS. Likewise chlorophyll-a, the BRRI dhan28 rice seedlings showed the superior due to higher chlorophyll-b synthesis during cold stress in the present study which seemed to be attributed by genetically. Similar observation was also obtained by Sarker et al. (2015) and Haque et al. (2016) [3, 13].

Table 4. Chlorophyll-b $\left(m g g^{-1}\right)$ synthesis by rice seedling of different cultivars at different $D A S$.

\begin{tabular}{llll}
\hline Cultivars & 16 DAS & 20 DAS & 24 DAS \\
\hline Binadhan-6 & $0.250 \mathrm{c} \pm 0.02$ & $0.399 \mathrm{bc} \pm 0.03$ & $0.399 \mathrm{c} \pm 0.07$ \\
BR-26 & $0.352 \mathrm{ab} \pm 0.10$ & $0.688 \mathrm{ab} \pm 0.27$ & $0.515 \mathrm{bc} \pm 0.29$ \\
BRRI dhan28 & $0.361 \mathrm{ab} \pm 0.03$ & $0.847 \mathrm{a} \pm 0.22$ & $0.725 \mathrm{a} \pm 0.15$ \\
BRRI dhan29 & $0.273 \mathrm{bc} \pm 0.04$ & $0.289 \mathrm{c} \pm 0.12$ & $0.610 \mathrm{ab} \pm 0.21$ \\
Banglamoti & $0.412 \mathrm{a} \pm 0.05$ & $0.451 \mathrm{~b} \pm 0.19$ & $0.537 \mathrm{~b} \pm 0.47$ \\
\hline
\end{tabular}

\subsection{Total Carotenoid Content}

The carotenoid production in rice plumule showed a sensitivity to ambient low temperatures in the field. In this study, a significant difference in carotenoid content was found among the seedlings of selected rice cultivars during the study period (Table 5). The overall study showed that the highest carotenoid content was happen in BRRI dhan28 (1.196 $\left.\mathrm{mg} \mathrm{g}^{-1}\right)$ and lowest value was observed in BRRI dhan29 $\left(0.300 \mathrm{mg} \mathrm{g}^{-1}\right)$ at $24 \mathrm{DAS}$ and $20 \mathrm{DAS}$, respectively. The total carotenoid content presented variable (Table 4) which seems to be attributed by genetically.

\subsection{Chlorophyll a/b Ratio}

In this study, a significant difference in chlorophyll-a/b ratio was found among the seedlings of selected rice cultivars during the experiment at low temperature. The variation of chlorophyll-a/b content is shown in Table 6 . At 16 DAS when the day of lowest temperature was $9^{\circ} \mathrm{C}$, the highest chlorophyll-a/b ratio was found in BRRI dhan28 (5.961) while the lowest value was observed in BRRI dhan50 (Banglamoti) (4.757).

Table 5. Total carotenoid content $\left(m g g^{-1}\right)$ in seedlings of different rice cultivars at different DAS.

\begin{tabular}{llll}
\hline Cultivars & 16 DAS & 20 DAS & 24 DAS \\
\hline Binadhan-6 & $0.433 \mathrm{~b} \pm 0.06$ & $0.560 \mathrm{ab} \pm 0.41$ & $0.802 \mathrm{ab} \pm 0.48$ \\
BR-26 & $0.607 \mathrm{a} \pm 0.05$ & $0.698 \mathrm{ab} \pm 0.03$ & $0.570 \mathrm{~b} \pm 0.30$ \\
BRRI dhan28 & $0.516 \mathrm{ab} \pm 0.01$ & $0.998 \mathrm{a} \pm 0.37$ & $1.196 \mathrm{a} \pm 0.87$ \\
BRRI dhan29 & $0.503 \mathrm{ab} \pm 0.10$ & $0.300 \mathrm{~b} \pm 0.11$ & $0.311 \mathrm{c} \pm 0.22$ \\
Banglamoti & $0.588 \mathrm{ab} \pm 0.13$ & $0.305 \mathrm{~b} \pm 0.43$ & $0.510 \mathrm{bc} \pm 0.28$ \\
\hline
\end{tabular}

At 20 DAS with air temperature $10^{\circ} \mathrm{C}$, the BRRI dhan 28 variety also had highest chlorophyll-a/b (3.659) and the lowest chlorophyll-a/b value was observed in BRRI dhan50 (3.231). The chlorophyll-a/b ratio of all cultivars at 20 and 24 DAS are statistically similar. The lowest chlorophyll-a/b ratio at 24 DAS was in BRRI dhan29 (2.903). 
Table 6. Chlorophyll-a/b ratio in rice seedlings of selected cultivars at different $D A S$.

\begin{tabular}{llll}
\hline Cultivars & 16 DAS & 20 DAS & 24 DAS \\
\hline Binadhan-6 & $4.874 \mathrm{~b} \pm 1.42$ & $3.244 \mathrm{ab} \pm 0.78$ & $3.575 \mathrm{ab} \pm 1.04$ \\
BR-26 & $5.759 \mathrm{a} \pm 1.66$ & $1.875 \mathrm{c} \pm 0.06$ & $2.972 \mathrm{~b} \pm 1.07$ \\
BRRI dhan28 & $5.961 \mathrm{a} \pm 0.27$ & $3.659 \mathrm{a} \pm 0.81$ & $5.387 \mathrm{a} \pm 4.84$ \\
BRRI dhan29 & $5.012 \mathrm{ab} \pm 1.15$ & $3.503 \mathrm{a} \pm 1.60$ & $2.903 \mathrm{~b} \pm 1.06$ \\
Banglamoti & $4.757 \mathrm{~b} \pm 0.86$ & $3.231 \mathrm{~b} \pm 1.23$ & $3.618 \mathrm{ab} \pm 0.88$ \\
\hline
\end{tabular}

\subsection{Relative Water Content}

Relative water content (RWC) of leaf is important characteristics that influence plant water relations. Relative water content is considered a measure of plant water status reflecting the metabolic activity in tissues and used as a most meaningful index for stress tolerance. The leaf RWC is mostly dependent on the canopy temperature. The variation in RWC obtained in this study might be due to the temperature variations during the experimental period. A significant variation in RWC of leaf among the selected rice cultivars was observed at different DAS during the experiment which is shown in Table 7.

Table 7. Relative water content (\%) of rice seedling at different DAS.

\begin{tabular}{llll}
\hline Cultivars & 16 DAS & 20 DAS & 24 DAS \\
\hline Binadhan-6 & $90.00 \mathrm{~ns} \pm 2.00$ & $87.67 \mathrm{~ns} \pm 2.52$ & $82.00 \mathrm{c} \pm 2.65$ \\
BR-26 & $88.67 \mathrm{~ns} \pm 4.04$ & $86.00 \mathrm{~ns} \pm 3.61$ & $80.00 \mathrm{c} \pm 2.00$ \\
BRRI dhan28 & $93.33 \mathrm{~ns} \pm 2.08$ & $92.00 \mathrm{~ns} \pm 3.61$ & $89.00 \mathrm{a} \pm 2.00$ \\
BRRI dhan29 & $89.00 \mathrm{~ns} \pm 2.00$ & $88.00 \mathrm{~ns} \pm 4.36$ & $84.33 \mathrm{bc} \pm 3.21$ \\
Banglamoti & $90.67 \mathrm{~ns} \pm 2.08$ & $90.33 \mathrm{~ns} \pm 1.53$ & $86.67 \mathrm{ab} \pm 1.53$ \\
\hline
\end{tabular}

Table 7 showed that the BRRI dhan 28 cultivar had the highest percentage of relative water content $(93.33 \%)$. The relative water content in the leaves of five cultivars was significantly different at 24 DAS. The BR-26 plants had the lowest percentage of relative water content $(80 \%)$ at 24 DAS.

\subsection{Starch Content}

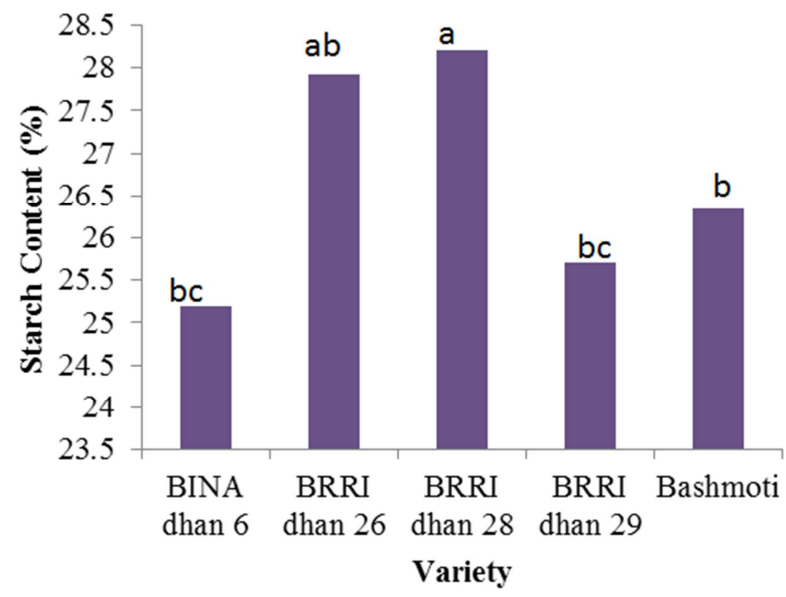

Figure 1. Starch content (\%) of rice seedlings in different rice cultivars.

In this study, a significant variation in plant starch content in selected rice cultivars at 24 DAS was found which is shown in Figure 1. Various soluble carbohydrates are considered as protective compatible solutes functioning during plant stress condition. It is assumed that cultivar having more percent starch content is comparatively low temperature stress tolerant than those of others.

These changes in cold tolerance and sugar content were not due to ontogenetic trends but were caused by cold acclimation by low temperature [8]. The present study with some rice cultivars has shown that starch content increased on exposure to low environmental temperature might be more cold tolerant at adverse stress.

\section{Conclusion}

It is evident that low temperature effectively enhanced the proline accumulation under chilling stress conditions. Higher quantity of chlorophyll-a and-b might have played protective role and also starch content helped for survival during low temperature environment that is important mechanism involved in increasing cold tolerance. To the conclude, the findings of this study showed that cold sensitivity of the tested HYV rice cultivars are related to the lower synthesis of proline content, chlorophylls and leaf starch in seedlings. Among the tested rice cultivars, BRRI dhan 28 showed better potentiality for cold survival mechanism at seedling stage based on over-synthesis of proline and higher content of chlorophyll pigment and starch content.

\section{References}

[1] A. Aghaee, F. Moradi, H. Zare-Maivan, F. Zarinkamar, H. P. Irandoostand and P. Sharifi, "Physiological responses of two rice (Oryza sativa L.) genotypes to chilling stress at seedling stage", Afri. J. Biotech., Vol. 10, pp. 7617-7621, 2011.

[2] B. C. Sarker, M. M. Haque, M. A. Bashar, B. Roy and M. S. Rahman, "Physiological responses of rice seedlings towards screening out cold tolerant rice cultivars in Northwest Bangladesh”, Asian J. Exp. Biol. Sci., Vol. 4, pp. 623-628, 2013.

[3] B. C. Sarker, M. U. Kulchhum, B. Roy, M. F. Hossain and M. M. Haque, "Cold tolerance mechanism of rice cultivars based on physio-morphological characteristics", J. Sci. Technol. (Dinajpur), Vol. 13, pp. 26-34, 2015.

[4] C. Somerville, "Direct tests of the role of membrane lipid composition in low temperature-induce photoinhibition and chilling sensitivity in plants and cyanobacteria", Proc. Natl Acad. Sci. (USA), Vol. 92, pp. 6215-6218, 1995.

[5] C. Y. Wang, "Physiological and biochemical responses of plants to chilling stress", Hortic. Sci., Vol. 17, pp. 173-186, 1982.

[6] D. I. Arnon, "Copper enzymes in isolated chloroplasts, polyphenol oxidase in Beta vulgaris L.”, Plant Physiol., Vol. 24, pp. 1-15, 1949.

[7] G. M. de Freitas, J. Thomas, R. Liyanage, J. O. Lay, S. Basu, V. Ramegowda, et al., "Cold tolerance response mechanisms revealed through comparative analysis of gene and protein expression in multiple rice genotypes”. PLoS ONE, Vol. 14 (6), e0218019, 2019. 
[8] H. Sasaki, K. Ichimura and M. Oda, "Changes in sugar content during cold acclimation and acclimation of cabbage seedlings", Ann. Bot., Vol. 78, pp. 365-369, 1996.

[9] K. Priyanka and H. K Jaiswal, "Effect of cold stress on boro rice seedlings", J. Appl. Nat. Sci., Vol. 9 (2), pp. 1036 - 1041, 2017.

[10] L. Jiang, M. M. Xun, J. L. Wang, J. M. Wan, "QTL analysis of cold tolerance at seedling stage in rice (Oryza sativa L.) using recombination inbred lines", Cereal Sci., Vol. 48, pp. 173-179, 2002.

[11] L. S. Bates, R. P. Waldren and I. D. Teare, "Rapid determination of free proline for water stress studies", Plant Soil, Vol. 39, pp. 205-208, 1973.

[12] M. F. Thomashow, "Plant Cold acclimation: Freezing tolerance genes and regulatory mechanisms". Annu. Rev. Plant Physiol. Plant Mol. Biol., Vol. 50, pp. 571-599, 1999.

[13] M. M. Haque, B. C. Sarker, M. Rahman, M. A. M. Sheikh and M. A. Hossain, "Cold survival potentiality of selected rice cultivars at seedling stage in Northwest Bangladesh", J. Sci. Technol. (Dinajpur), Vol. 14, pp. 62-69, 2016.

[14] N. Tuteja, S. S. Gill, A. F. Tiburcio and R. Tuteja, "Rice: improving cold stress tolerance- Improving crop resistance to abiotic stress", (Ed). John Wiley \& Sons, Inc. Vol. 1 \& 2, pp. 1-456, 2012.

[15] P. D. Hare and W. A. Cress, "Metabolic implications of stress-induced proline accumulation in plants", Plant Growth Regulation, Vol. 21, pp. 79-102, 1997.

[16] P. D. Hare, W. A. Cress and J. Van Staden, "Dissecting the roles of osmolyte accumulation during stress", Plant Cell Environment, Vol. 21, pp. 535-553, 1998.

[17] P. Haldimann, "How do changes in temperature during growth affect leaf pigment composition and photosynthesis in Zea mays genotypes differing in sensitivity to low temperature?" J. Expt. Bot., Vol. 50, pp. 543-550, 1999.
[18] Q. W. Jiang, O. Kiyoharu and I. Ryozo, "Two novel mitogen-activated protein signaling components, OsMEK1 and OsMAP1, are involved in a moderate low-temperature signaling pathway in rice", Plant Physiol., Vol. 129, pp. 1880 $1891,2002$.

[19] R. J. Porra, "The chequered history of the development and use of simultaneous equations for the accurate determination of chlorophylls a and b", Photosynthesis Research, Vol. 73, pp. 149-156, 2002.

[20] R. P. Cruz and S. C. K. Milach, "Cold tolerance at the germination stage of rice: methods of evaluation and characterization of genotypes", Sci. Agric. (Piracicaba, Braz.), Vol. 61, pp. 1-8, 2004.

[21] S. K. Yadav, "Cold stress tolerance mechanisms in plants- A review”, Agron. Sustain. Dev., Vol. 30, pp. 515-527, 2010.

[22] S. Kim, D. Kim and T. H. Tai, "Evaluation of rice seedling tolerance to constant and intermittent low temperature stress", Rice Science, Vol. 19, pp. 1-14, 2012.

[23] S. Zhang, H. Jiang, S. Peng, H. Korpelainen and C. Y. Li, "Sex-related differences in morphological, physiological, and ultrastructural responses of Populus cathayana to chilling", J. Exp. Bot., Vol. 62, pp. 675-686, 2010.

[24] T. Nanjo, M. Kobayashi, Y. Yoshiba, Y. Kakubari, K. Yamaguchi-Shinozaki and K. Shinozaki, "Antisense suppression of proline degradation improves tolerance to freezing and salinity in Arabidopsis thaliana", FEBS Lett., Vol. 461, pp. 205-210, 1999.

[25] W. W. Yan, L. P. Bai, L. Zhang, G. Chen, J. G. Fan, X. H. Gu, W. S, Cui and Z. F, Guo, "Comparative study for cold acclimation physiological indicators of Forsythia mandshurica Uyeki and Forsythia viridissima", Ind. Middle-East J. Sci. Res., Vol. 6, pp. 556-562, 2010. 